Organ culture:

Artificial hearts, lungs and livers offer hope to transplant patients

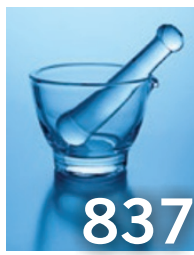

In rare form:

Big pharma steps

into orphan drug

market

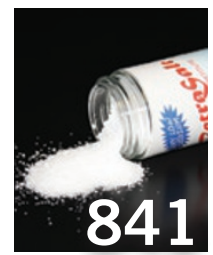

Grain of salt:

New salt substitutes aim to reduce heart attack risks

\title{
After Avandia, some seek split in drug approval and monitoring
}

GlaxoSmithKline's blockbuster diabetes drug Avandia (rosiglitazone) has been in the hot seat ever since a 2007 meta-analysis called the medicine's safety into question. At the time, a panel of experts convened by the US Food and Drug Administration (FDA) voted 20-3 that Avandia increased cardiovascular risk, but then 22-1 that the benefits of the drug outweighed the risks.

Now, spurred on by a growing number of studies indicating that Avandia triggers more heart attacks than its competitor Actos (made by Takeda), two FDA advisory committees convened again last month to decide whether to pull Avandia from the market. In a split decision, 22 of 33 panelists voted to either withdraw the drug completely or to heavily restrict its use.

As Nature Medicine went to press, FDA commissioner Margaret Hamburg had yet to make the final decision about Avandia's future. But the panel's mixed verdict has prompted some public health researchers to wonder aloud whether the same officials who approve medicines should also be the

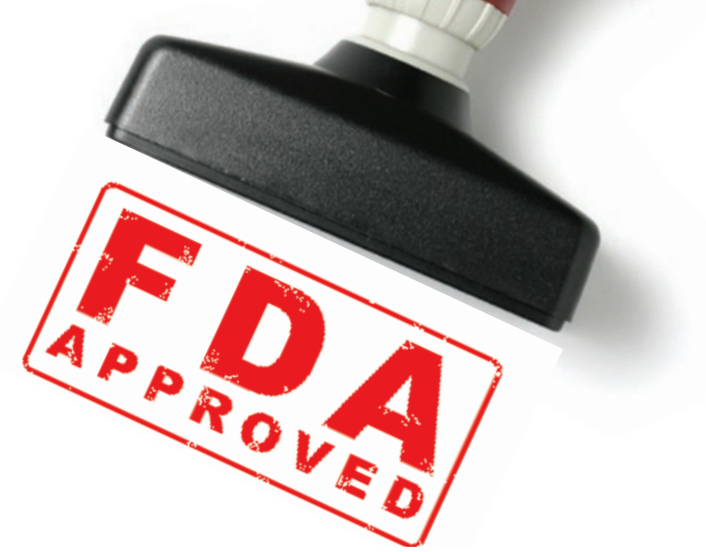

Sealed up: Stamping down on Avandia. ones making crucial after-the-fact decisions regarding safety.

"The fundamental structural defect in FDA handling of drug safety is that the people who approve the drugs are the ones who sit in judgment of them once they're approved," says FDA epidemiologist David Graham, who published the most recent salvo against Avandia in June (J. Am. Med. Assoc. doi:10.1001/jama.2010.920, 2010) and testified before the advisory committee. "These people are basically captive to their prior decisionsthat's human nature."

After Merck's painkiller Vioxx (rofecoxib) was yanked from the market in 2004, Graham and others-most notably congressional rabble-rouser Charles Grassley, the Republican senator from Iowa-repeatedly called for a separate regulatory agency outside the FDA to conduct post-approval risk-benefit analyses of marketed drugs. In 2005, the FDA created a Drug Safety Oversight Board under the auspices of the agency's Center for Drug Evaluation and Research, but it stopped short of handing off the agency's post-approval duties to an independent body. The Avandia case, critics maintain, demonstrates that these changes did not go far enough.

"Drug safety is like a stepchild-it doesn't have equal status as efficacy in the evaluation and in staffing," says Curt Furberg, a health policy expert at Wake Forest University School of Medicine in Winston-Salem, North Carolina, and a member of the FDA advisory panel who voted to withdraw Avandia from the market. "What we need is a strong, separate unit [for evaluating safety]; it should not be a subunit of efficacy."

"The burden of getting [a drug] restricted or even off the market is very high," adds Art Levin, director of the Center for Medical Consumers in New York. "In this country at least, the off button is so rarely switched that you need other options."

\section{Ideas in flight}

Proponents of a two-agency solution look to the US aviation industry for guidance. In that field, the Federal Aviation Administration regulates the country's skies unless something goes wrong, in which case the National Transportation Safety Board steps in. Yet unlike a plane crash, which presents no possible advantage to airplane passengers, the risks of problematic drugs must be weighed against the benefits they afford to people who are ill, notes John Cohrssen, an attorney who worked on FDA reform during the 1990s as majority counsel of the US House Commerce Committee. With medicine, he says, "there's no black box."

Not everyone is convinced a two-agency structure is the way forward. Henry Miller, a former FDA official and a fellow at Stanford University's Hoover Institution in California, questions the logic of granting final say on safety to officials with less clinical expertise than FDA scientists. "Splitting the functions [of safety and efficacy approval] is a good ivory tower idea, but it just doesn't work with realworld experience," he says.

Kenneth Kaitin, director of the Tufts Center for the Study of Drug Development in Boston, sees considerable improvements in the safety evaluation process at the FDA, particularly in the area of safety monitoring. For example, since 2002 the agency has started tracking postmarketing research requirements, applying user fees toward post-marketing surveillance and requiring risk-evaluation mitigation strategies from drug makers. "The FDA is now going to be looking into what is your plan once the drug has entered the market, which isn't a bad idea," Kaitin says.

Prompted by the Avandia controversy, in April Hamburg asked the US Institute of Medicine (IOM) to look into the ethical issues raised by probing the safety of alreadyapproved drugs. On 9 July, the IOM released a slim, 26-page preliminary report outlining vague principles and recommendations for when randomized clinical trials to evaluate potential safety risks of marketed drugs are in order. A more thorough IOM review detailing the ethics of post-market clinical trials will be completed next spring. Meanwhile, European regulators announced last month that they also plan to review Avandia’s safety.

Elie Dolgin 